\title{
Behavioral changes associated with fever in transition dairy cows
}

J. Lomb, M. A. G. von Keyserlingk, (1) and D. M. Weary* (이

Animal Welfare Program, Faculty of Land and Food Systems, University of British Columbia, 2357 Mall, Vancouver, BC, Canada V6T 1Z4

\begin{abstract}
Dairy cows are often diagnosed with fever without showing clinical symptoms of disease. The aim of this study was to investigate changes in feeding, social, and lying behaviors of cows with fever but without clinical disease, as compared with healthy cows. After parturition, dairy cows of mixed parities were housed in a dynamic group of 20 . In the freestall pen, cows had access to 12 electronic feed bins, 2 electronic water bins, and 24 lying stalls. Feeding and social behaviors were recorded using the electronic feed bins, and lying behaviors were measured using electronic data loggers attached to the cow. Rectal body temperature was assessed on a daily basis, and fever defined as a body temperature $>39.5^{\circ} \mathrm{C}$. All cows were examined for metritis every third day after calving, and all other diseases (e.g., mastitis, ketosis) were diagnosed as per farm protocol. Cows with multiple days of fever $(\mathrm{n}=$ 8) and cows with $1 \mathrm{~d}$ of fever $(n=18)$ that were not diagnosed with a clinical disease were compared with a matched sample of healthy cows (i.e., cows that were not clinically ill and never had a fever recorded) of the same parity (categorized as primiparous vs. multiparous). Feeding, social, and lying behaviors were compared for the first $2 \mathrm{~d}$ of fever in cows with multiple days of fever, and the day of fever in cows with $1 \mathrm{~d}$ of fever. Cows of both fever groups spent less time feeding compared with controls (135 vs. $181 \pm 7.6 \mathrm{~min} / \mathrm{d}$ for multiple fever days, and 158 vs. $185 \pm 9.7 \mathrm{~min} / \mathrm{d}$ for $1 \mathrm{~d}$ of fever). Cows with $1 \mathrm{~d}$ of fever ate at a faster rate (109 vs. $91 \pm 5 \mathrm{~g} / \mathrm{min}$ ) and had a lower number of replacements at the feed bunk (actor replacements: 9.7 vs. 14.6 \pm 1.7 no. $/$ d; reactor replacements: 11.1 vs. $15.9 \pm 1.6$ no./d) compared with healthy controls. Overall, cows with fever showed behavioral changes such as decreased feeding time that are consistent with sickness responses described in other species.
\end{abstract}

Received November 9, 2018.

Accepted March 31, 2020.

*Corresponding author: dan.weary@ubc.ca
Key words: sickness behavior, feeding, lying, social

\section{INTRODUCTION}

Dairy cows in the weeks around calving have a high incidence of illness (Mulligan and Doherty, 2008; LeBlanc, 2010). Behavioral changes associated with infectious disease have been described in a variety of species (typically referred to as sickness behaviors; Hart, 1988; Shakhar and Shakhar, 2015). Reduced feed intake, reduced social interactions, and reduced activity have been identified in transition cows in the days leading up to clinical diagnosis of metritis and mastitis (Sepúlveda-Varas et al., 2016; King et al., 2018; Neave et al., 2018).

During transition, many cows show evidence of fever [i.e., rectal body temperature $(\mathbf{B T})>39.5^{\circ} \mathrm{C}$, Suthar et al., 2012] without other signs of illness (Wenz et al., 2011; Sutherland et al., 2012). It is difficult to classify such individuals as either sick or healthy. Fever and behavioral signs of sickness are often closely related and mediated through similar immunological and hormonal pathways (Bleeker-Rovers et al., 2009; Pecchi et al., 2009). For example, mid-lactation cows challenged intravenously with LPS exhibit fever and reduced DMI (Waldron et al., 2003; Zhao et al., 2018). However, little work has examined the relationship between fever and behavior in transition dairy cows.

The objectives of this study were to describe changes in feeding, social, and lying behaviors of transition dairy cows with one and multiple days of fever (defined as rectal $\mathrm{BT}>39.5^{\circ} \mathrm{C}$ ) but not showing other signs of clinical disease. We hypothesized that cows experiencing fever would differ in behavior compared with control cows with normal BT.

\section{MATERIALS AND METHODS}

Data for this study were from a larger project [University of British Columbia (UBC) Animal Ethics Committee protocols A10-0163 and A14-0040] that focused on the behavior of healthy transition cows (Neave et al., 2017), behavioral changes before metritis diagnosis (Neave et al., 2018), and the effect of treatment with 
the nonsteroidal anti-inflammatory drug meloxicam on sickness behavior of dairy cows with metritis (Lomb et al., 2018). Cows were followed from July 2014 to October 2014 at the UBC Dairy Education and Research Centre in Agassiz, British Columbia, Canada, and were cared for following the guidelines of the Canadian Council on Animal Care (2009).

\section{Animals, Management, and Housing}

Health and behavior of initially healthy and nonlame primiparous $(\mathrm{n}=105)$ and multiparous $(\mathrm{n}=232)$ Holstein cows were monitored from approximately 3 wk before to 3 wk after calving. An additional 30 cows were followed for only part of the transition period; 16 cows were dropped after calving because there was no space in the postpartum pen (no cow was available to move from the postpartum pen that was at least 21 DIM) or because they were assigned to a different study, and 14 cows that had been moved to the postpartum pen were moved out before 21 DIM. Of these, 4 were moved to a hospital pen to receive treatment, and 10 were diagnosed with a disease other than metritis and moved to make space for newly calved cows. Cows were first housed in a prepartum pen and then moved to a postpartum pen within $24 \mathrm{~h}$ of calving. When a new cow was moved to the postpartum pen, the resident cow with the highest DIM was moved out (and left the study) to maintain a constant group size of 20 cows. Both pens were fitted with 12 electronic feed bins (Insentec, Marknesse, Holland), 2 electronic water bins of the same system, and 24 lying stalls. The lying stalls were equipped with mattresses (Pasture Mat, Promat Inc., Woodstock, Ontario, Canada) covered with approximately $5 \mathrm{~cm}$ of sand.

When a pregnant cow in the prepartum pen showed imminent signs of calving (i.e., relaxation of tail ligament, milk let down), she was moved to a calving pen. The calving pen contained a sawdust open pack and cows had access to 1 electronic water and 6 electronic feed bins, of which 1 was filled per cow in the pen (maximum 2 cows at the same time).

Cows were fed ad libitum a TMR meeting or exceeding NRC (2001) requirements. The prepartum cow TMR included $32 \%$ corn silage, $37 \%$ alfalfa hay, $18 \%$ rye grass straw, and $13 \%$ concentrate (DM: $52.4 \pm 4.7 \%$; CP: $14.3 \pm 0.34 \%$ DM; ADF: $34.6 \pm 0.60 \%$ DM; NDF: $46.5 \pm 0.17 \% \mathrm{DM}$; and $\mathrm{NE}_{\mathrm{L}}: 1.39 \pm 0.0071 \mathrm{Mcal} / \mathrm{kg}$ ). The postpartum cow TMR included $26 \%$ corn silage, $13 \%$ grass silage, $7 \%$ alfalfa hay, $4 \%$ grass hay, and $50 \%$ grain concentrate mash (DM: $50.35 \pm 2.5 \%$; CP: 18.3 $\pm 0.58 \%$ DM; ADF: $18.1 \pm 0.71 \%$ DM; NDF: $28.5 \pm$ $1.2 \% \mathrm{DM}$; and $\left.\mathrm{NE}_{\mathrm{L}}: 1.72 \pm 0.014 \mathrm{Mcal} / \mathrm{kg}\right)$. Fresh feed was delivered twice daily, at approximately 0800 and 1600 h. After calving, cows were milked twice per day at 0700 and $1700 \mathrm{~h}$.

After calving, all signs of illness were recorded. For the purpose of metritis examination, cows were retained in a sorting area after morning milking (between 0800 and $1000 \mathrm{~h}$ ) on every third day after calving, beginning at 3 DIM until 21 DIM. Metritis was diagnosed by 2 trained researchers. The diagnosis was based on vaginal discharge, collected with a gloved hand and scored on a scale from 0 to 4 , where $0=$ healthy and $4=$ severe metritis (i.e., watery, foul-smelling discharge; Huzzey et al., 2007). Farm staff monitored all cows for other transition cow diseases, including ketosis, downer cow syndrome, and displaced abomasum, and recorded and treated these according to farm protocol; diagnosis and treatment records were then immediately shared with the researchers. Details on farm protocols to identify ill cows are described by Neave et al. (2017). Briefly, cows were screened for mastitis twice daily during regular milking routine, based on appearance of the udder and milk quality. When a cow presented with reduced feed intake and milk yield, milk strips (KetoTest, Elanco Animal Health, Nagoya, Japan) were used to confirm ketosis. Displaced abomasum was diagnosed by the herd veterinarian after farm staff had identified cows with a typical metallic sound when auscultating the left flank.

During the first 21 DIM, rectal temperature was either taken when cows were restrained in head locks during health checks (every 3 DIM between 0800 and $1000 \mathrm{~h}$ ), or in the pen, when most cows were settled in the lying stalls after morning milking (all other days between 1000 and $1200 \mathrm{~h}$ ). When taken during the health check, BT was taken before any other procedures were performed. Body temperature was measured using an electronic thermometer (Nexcare Rapid Digital Thermometer, $3 \mathrm{M}$, St. Paul, MN) inserted $\sim 10 \mathrm{~cm}$ and ensuring contact with the rectal wall. The measurement was taken when an acoustic signal was given by the thermometer. Body temperature was taken by multiple observers (n $>5$ ) who all were trained and monitored by 1 of the 2 main researchers when performing the procedure during the health check and in the pen. Body temperature measures (measured as rectal temperature) by different trained observers are known to be highly correlated ( $\mathrm{r}$ $=0.96$; Burfeind et al., 2010).

\section{Study Animals}

Cows with Fever. All cows that were clinically healthy (i.e., had no signs of disease) but had at least $1 \mathrm{~d}$ of fever $\left(\mathrm{BT}>39.5^{\circ} \mathrm{C}\right)$ at $\geq 2$ DIM (i.e., after they 
Table 1. The number of multiparous and primiparous cows and mean $( \pm \mathrm{SD})$ lactation number and DIM, shown separately for cows with $1 \mathrm{~d}$ and multiple days of fever, and for healthy control cows matched by DIM

\begin{tabular}{lccccc}
\hline & \multicolumn{2}{c}{ Multiple days of fever } & & \multicolumn{2}{c}{$1 \mathrm{~d}$ of fever } \\
\cline { 2 - 3 } \cline { 5 - 6 } Item & Fever & Healthy & & Fever & Healthy \\
\hline Multiparous (no.) & 8 & 8 & 8 & 9 \\
Primiparous (no.) & 0 & 0 & & 10 & 9 \\
Lactation & $3.1 \pm 0.8$ & $3.0 \pm 0.8$ & & $2.3 \pm 1.9$ & $1.5 \pm 1.7$ \\
DIM (d) & $6.4 \pm 3.5$ & $6.4 \pm 3.5$ & & $10.9 \pm 4.7$ & $10.9 \pm 4.7$ \\
\hline
\end{tabular}

had been moved to the postpartum pen) were eligible to be part of the study, provided that they remained in the experimental pen for the entire $21 \mathrm{~d}$ postpartum. Expecting that the behavioral effects of bouts of fever lasting more than $1 \mathrm{~d}$ may differ, we distinguished between bouts lasting 2 or more consecutive days $(\mathrm{n}=8$; average duration of consecutive fever days: $2.5 \pm 0.76$ d) versus those lasting just $1 \mathrm{~d}(\mathrm{n}=18)$. Cows were categorized as having multiple days of fever when they had 2 or more consecutive days of fever, but not an intermittent fever where fever bouts were interrupted with days of normal BT. When cows had more than 2 consecutive days of fever, only the first 2 fever days were considered for analysis. Cows with $1 \mathrm{~d}$ of fever were categorized as such when they had $1 \mathrm{~d}$ of fever, had a normal BT in the remaining $20 \mathrm{~d}$ period, and no missing BT in the $3 \mathrm{~d}$ leading up to and after the day of fever. However, within the 20-d period, most cows had at least $1 \mathrm{~d}$ of missing BT data. Out of the 8 cows with multiple days of fever, 3 cows had $1 \mathrm{~d}$ of missing BT data, and 3 cows had $2 \mathrm{~d}$ of missing BT data. Out of the 18 cows with $1 \mathrm{~d}$ of fever, some BT data were not available for 11 cows; $1 \mathrm{~d}$ was missing for 6 cows, and 2 d were missing for 5 cows; see Supplemental Table S1 (https://doi.org/10.3168/jds.2018-15969) for details on missing BT data.

The majority of fever cows calved unassisted or were assisted with an easy pull (i.e., one-person pull when the legs of the calf were already visible). All but 1 cow with multiple days of fever calved unassisted, and 1 cow's calving ease was recorded as easy pull. Out of the 18 cows with 1 d of fever, 10 cows calved unassisted, 3 required an easy pull, 3 were recorded as hard pull (i.e., 2-person pull), and for 2 cows calving ease was not recorded.

Control Cows. During the study period, 112 cows were clinically healthy and never recorded with a BT $>39.5^{\circ} \mathrm{C}$; we refer to these as healthy cows. Given that feeding and lying behaviors are highly variable in the first weeks of lactation (Huzzey et al., 2005; Kaufman et al., 2016), we compared each fever cow with one healthy cow on the same day of lactation (e.g., when fever occurred on d 4 of lactation in a sick animal, her data were compared with the same day of lactation for her matched control; in cases of multiple days the values were averaged across both days). For each cow with fever the next cow that calved was selected, provided that (1) she was healthy (i.e., not diagnosed with a clinical disease) and she did not have a fever (BT $\left.\leq 39.5^{\circ} \mathrm{C}\right)$, (2) she was in the same parity group (i.e., primiparous or multiparous), and (3) no more than 2 $\mathrm{d}$ of BT were missing. Of the 8 controls for cows with multiple days of fever, $1 \mathrm{~d}$ of BT data were missing for 1 cow. Of the 18 control cows for cows with $1 \mathrm{~d}$ of fever, $1 \mathrm{~d}$ of BT data were missing for 3 cows and $2 \mathrm{~d}$ of BT data were missing for 1 cow (see Supplemental Table S1 for details; https://doi.org/10.3168/jds.2018 -15969). All but 7 control cows calved unassisted; of the remaining cows, 5 were assisted with an easy pull $(\mathrm{n}=$ 5 ) and for the 2 other calving ease was not recorded. Details on both health groups are summarized in Table 1.

\section{Behavioral Measures}

Feeding behaviors were measured using the electronic feed bins. Cows were fitted with ear transponders (High Performance ISO Half Duplex Electronic ID Tag by Allflex Inc., St. Hyacinthe, Quebec, Canada) that registered when a cow entered a specific bin and recorded the difference in weight of feed from when she entered and exited the bin (described and validated by Chapinal et al., 2007). These data were used to calculate DMI $(\mathrm{kg} / \mathrm{d})$, feeding time $(\mathrm{min} / \mathrm{d})$, and the number of times a cow entered a feed bin (i.e., visits) per day. We further calculated the number of daily meals with a new meal being recorded when a cow had not visited the feeder for a minimum of 20.1 min (Proudfoot et al., 2009). Last, we calculated the feeding rate as grams of DMI per minute spent at the feed bunk.

Data from the electronic feed bins were used to estimate the number of competitive replacements from the feeder. A replacement was recorded when one cow (i.e., actor) physically contacted another cow and this second cow (i.e., reactor) exited the feed bin. As validated by Huzzey et al. (2014), a threshold of $26 \mathrm{~s}$ between 2 
consecutive visits at one feed bin was used to identify a replacement.

Lying behavior was monitored using electronic data loggers (HOBO Pendant G Acceleration Data Logger, Onset Computer Corporation, Pocasset, MA) fitted onto a hind leg using elastic bandages (Co-Flex, Andover Coated Products Inc., Salisbury, MA). Loggers were set to record the g-forces on 2 axes (y-and $\mathrm{x}$-axis) at 1-min intervals. Data were downloaded weekly when loggers were changed and summarized into daily lying behavior [i.e., lying time $(\mathrm{min} / \mathrm{d})$, number of lying bouts (no./d), and average lying bout duration ( $\mathrm{min} /$ bout)] using the UBC Animal Welfare Program (2013) algorithm and the cut-off described by Ledgerwood et al. (2010). Due to logger failure, lying data were not available for 4 cows of the 1 -d fever group.

\section{Statistical Analyses}

All statistical analyses were performed using SAS (version 9.4, SAS Institute Inc., Cary, NC). Data were summarized to provide one data point per cow for each dependent variable. All variables were scrutinized for normality and outliers using PROC UNIVARIATE.

Differences between fever and control cows were analyzed separately for cows with $1 \mathrm{~d}$ of fever and cows with multiple days of fever. A general linear model was used for both analyses, with cow as the experimental unit. The DIM on day of fever, health status (fever vs. healthy), and the interaction of DIM and health status were offered to the model as fixed effects. Daily maximum ambient temperature was obtained through records provided by the Environment Canada weather station in Agassiz. Ambient temperature and its interaction with health status were offered to both models; these effects were never significant and in the majority of models did not improve fit (as determined by Akaike information criterion), so these were omitted from the final analysis. Parity (primiparous vs. multiparous) was included as a fixed effect for the analysis of cows with $1 \mathrm{~d}$ of fever (there were no primiparous cows with multiple days of fever).

In the preliminary analysis of cows with multiple days of fever, we used a mixed model with day of fever as a repeated measure; the interaction of health status and day of fever was never significant, so values were averaged across the multiple days to generate one data point per cow. Therefore, the final model did not include repeated measures, and data were analyzed using the general linear model described above.

Significance level was set at $P \leq 0.5$, and a tendency at $P \leq 0.10$. Interactions were retained in the model when $P<0.1$.

\section{RESULTS}

\section{Cows with Multiple Days of Fever}

No difference was observed in feed intake between cows with and without fever, but cows with a fever spent less time at the feeder $\left(F_{1,13}=18.74, P<0.001\right.$; Figure 1). An interaction was present between fever and DIM for number of feeder visits $\left(F_{1,12}=5.45, P\right.$ $=0.04$ ), but this was driven by a single cow high in both visits and DIM (Figure 2). An interaction was also present between fever and DIM for feeding rate $\left(F_{1,12}=\right.$ 13.73, $P<0.01)$; this interaction was due to the effect of fever being more pronounced later in lactation. The number of meals did not differ with fever status.

Fever had no effect on competitive replacements from the feeder (as either actor or reactor; Table 2). For time spent lying, there was a tendency for an interaction between fever and DIM $\left(F_{1,12}=4.4, P=0.06\right)$, where the effect of fever was greater early in lactation. Fever had no effect on the number or duration of lying bouts.

\section{Cows with $1 d$ of Fever}

No difference was observed in feed intake between cows with and without fever, but cows with fever spent less time at the feed bunk $\left(F_{1,32}=4.0, P=0.05\right)$. For feeder visits, there was a tendency for an interaction between fever and DIM $\left(F_{1,31}=3.02, P=0.09\right)$, such that the effect of fever was greater early in lactation. Cows with fever had a faster feeding rate than healthy cows $\left(F_{1,32}=6.88, P=0.01\right)$.

Cows with fever were less likely to displace other cows from the feed bunk $\left(F_{1,32}=4.29, P=0.05\right)$ and were less likely to be replaced by other cows $\left(F_{1,32}=\right.$ 4.39, $P=0.04)$ relative to healthy cows. Fever had no effect on any measure of lying behavior.

\section{DISCUSSION}

Cows with fever showed behaviors consistent with the expression of sickness behaviors. The effect of fever differed between cows with more than $1 \mathrm{~d}$ of fever versus just $1 \mathrm{~d}$ of fever, perhaps due to differences in the samples; all cows with multiple days of fever were multiparous, but the one-day sample included both primiparous and multiparous cows, and parity is known to affect these behaviors (Neave et al., 2017).

The most pronounced and consistent finding was that cows with fever (on one or more days) spent less time at the feeder. Feeding time and feed intake are imperfectly related (Johnston and DeVries, 2018). Anorexia is considered a sickness behavior in many species (Hart, 
1988; Tizard, 2008), and reduced feeding time has been observed in dairy cows following a LPS challenge (Waldron et al., 2003; Zhao et al., 2018). Our findings suggest that reduced feeding time may be a more sensitive and reliable indicator of fever than reduced feed intake.
Decreased feeding time is also consistent with a more general decrease in activity, as commonly seen in sick animals (Hart, 1988). In the current study we did not include other measures of activity, but encourage these to be considered in future work. a

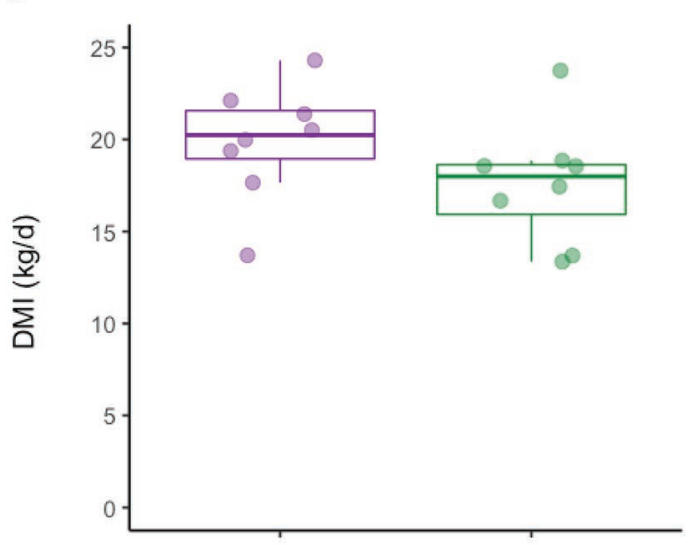

C

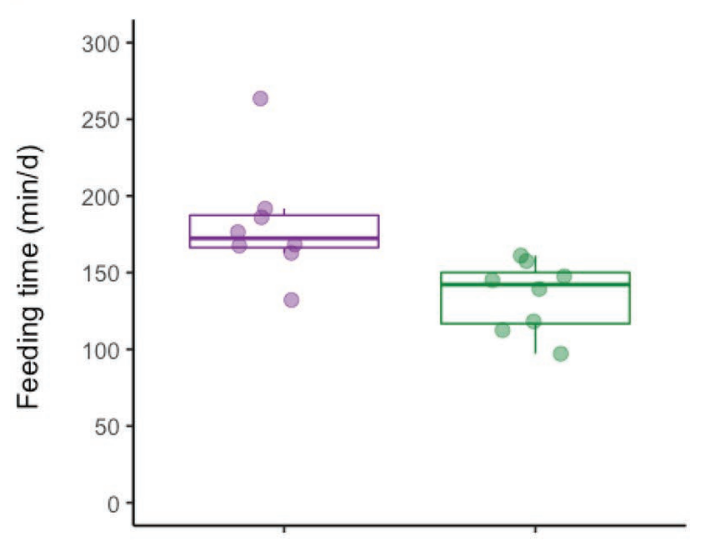

b

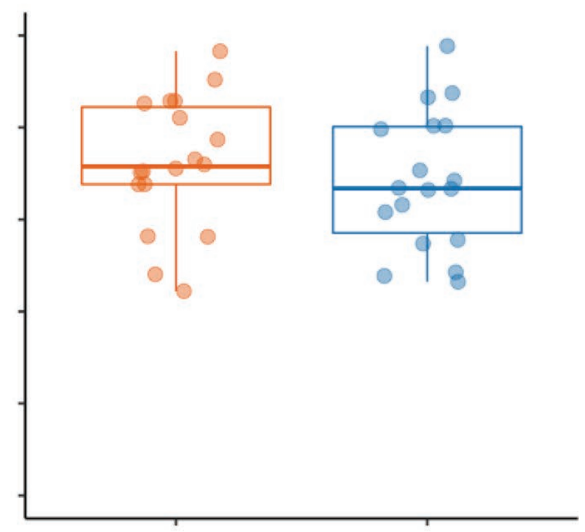

d

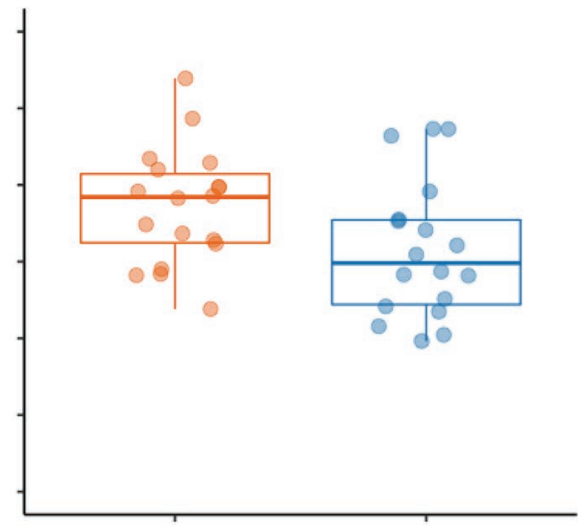

e

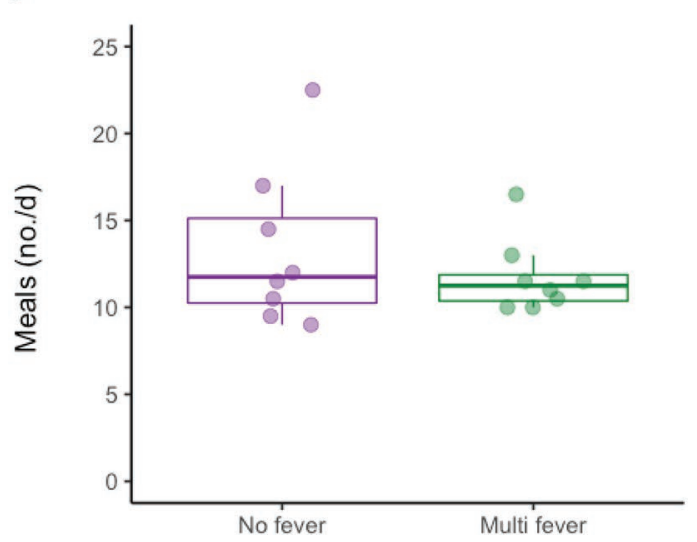

$\mathbf{f}$

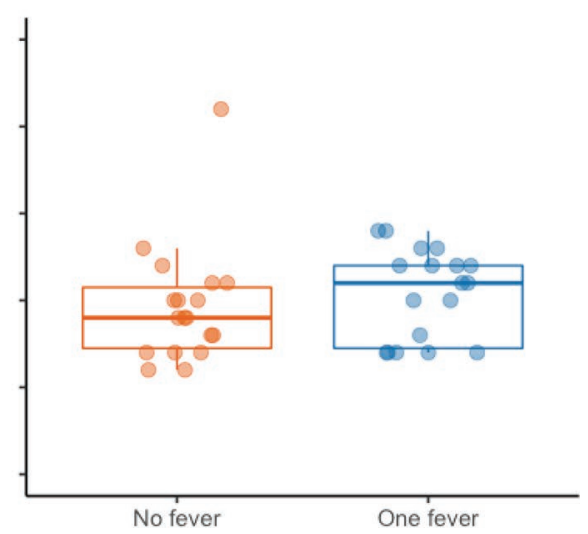

Figure 1. Feed intake on a DM basis (kg/d; panels a, b), feeding time (min/d; panels c, d), and meals (no./d; panels e, f). Results are shown separately for cows with multiple days of fever (panels a, c, and e; $\mathrm{n}=8$; averaged for the first $2 \mathrm{~d}$ of fever) and $1 \mathrm{~d}$ of fever (panels b, $\mathrm{d}$, and $\mathrm{f} ; \mathrm{n}=16)$ compared with healthy controls. Dots depict data of individual animals. Horizontal lines of the boxes indicate lower quartile, median, and upper quartile. Whiskers show 95\% CI. Please refer to text for inferential test statistics. 
a
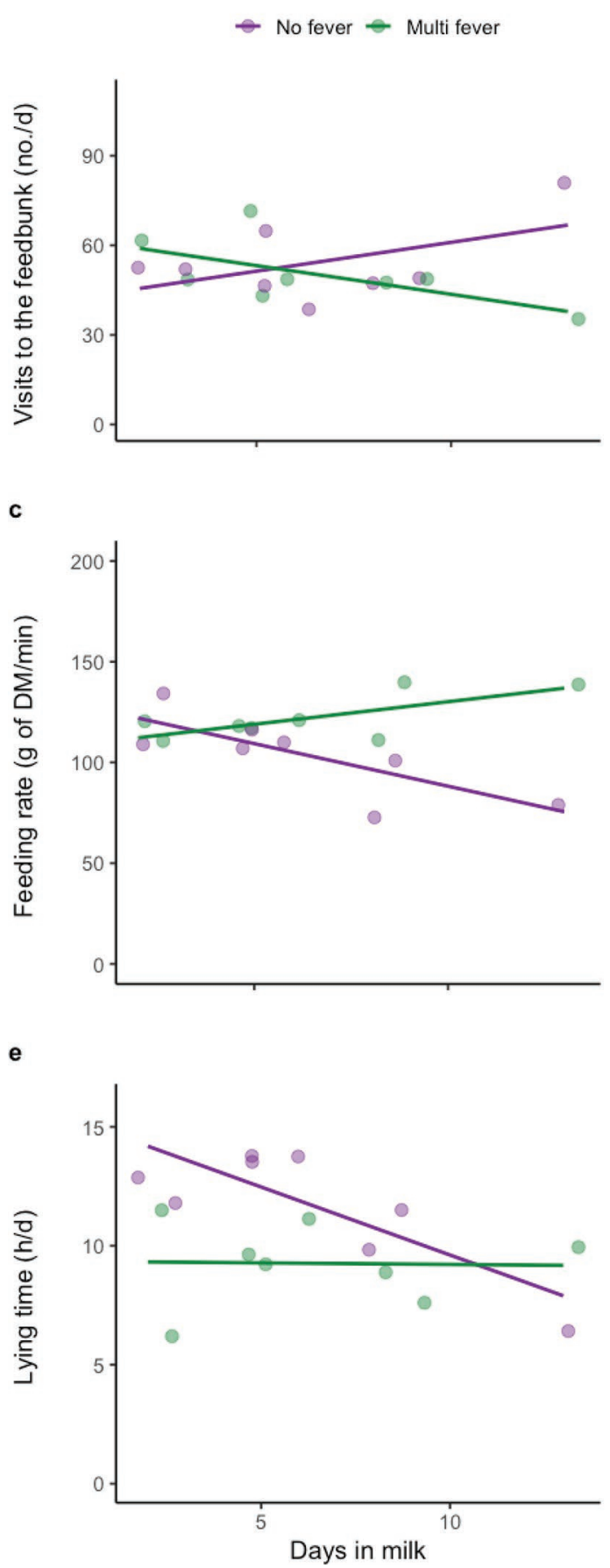

b

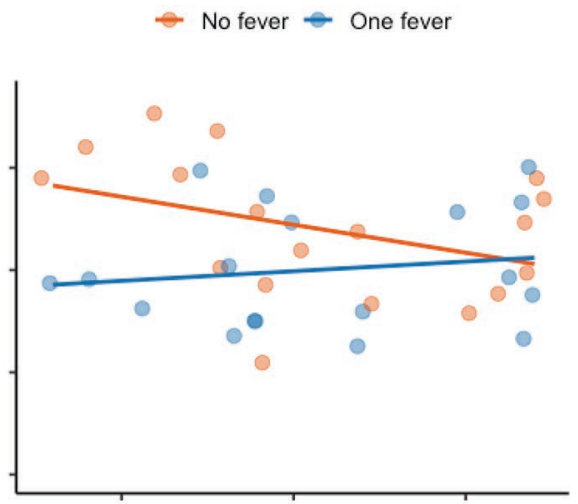

d

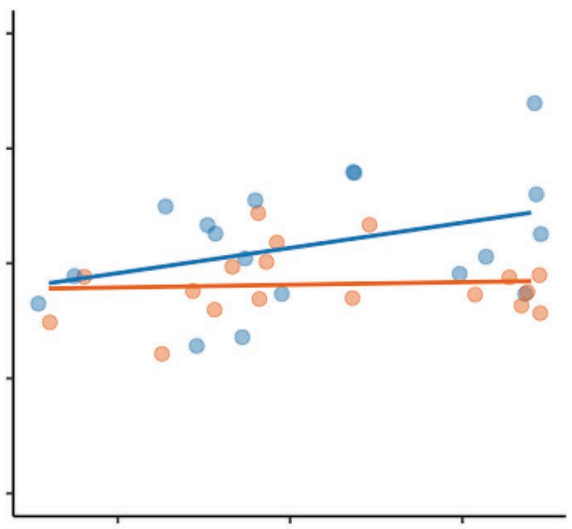

f

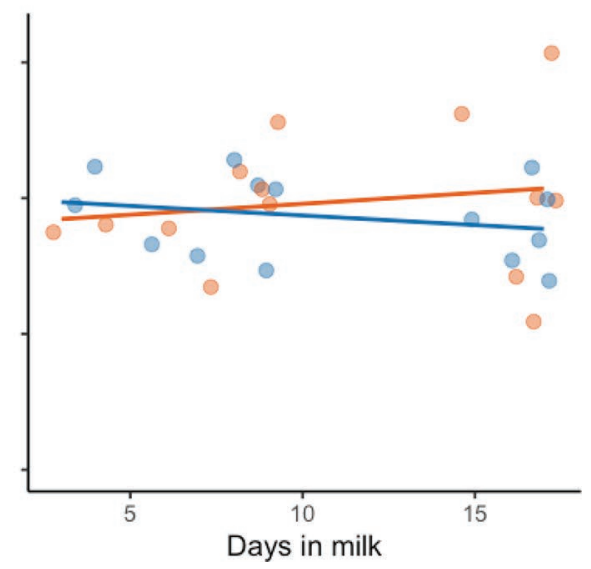

Figure 2. Changes in feeder visits (number; panels a and b), changes in feeding rate (g/min; panels c and d), and lying time (h/d; panels $\mathrm{e}$ and $\mathrm{f}$ ) in relation to stage of lactation (DIM). Results are shown separately for cows with multiple days of fever (panels a, $\mathrm{c}$, and e; $\mathrm{n}=8$; averaged for the first $2 \mathrm{~d}$ of fever) and $1 \mathrm{~d}$ of fever (panels $\mathrm{b}, \mathrm{d}$, and $\mathrm{f} ; \mathrm{n}=16 ; \mathrm{n}=14$ for lying time) compared with healthy controls. Please refer to text for inferential test statistics.

Some of the other behavioral changes observed in our study were in line with changes previously described in transition cows with clinical infectious disease. For example, previous work has shown that cows with me- tritis and mastitis (with or without fever) engage in fewer social interactions in the days before diagnosis (Sepúlveda-Varas et al., 2016; Neave et al., 2018), a finding consistent with our results for cows with $1 \mathrm{~d}$ of 
Table 2. Least squares means $( \pm \mathrm{SE})$ of the number of replacements at the feed bunk (showing actor and reactor replacements separately), and lying behaviors, for cows with multiple days of fever $(n=8$; average of the first $2 \mathrm{~d}$ of fever and compared with healthy controls matched for DIM) and $1 \mathrm{~d}$ of fever $(\mathrm{n}=18$ for replacements, $\mathrm{n}=14$ for lying behaviors; compared with healthy controls matched for DIM)

\begin{tabular}{|c|c|c|c|c|c|c|c|c|}
\hline Behavior & \multicolumn{4}{|c|}{ Multiple days of fever } & \multicolumn{4}{|c|}{$1 \mathrm{~d}$ of fever } \\
\hline Actor replacements $^{1}$ (no./d) & 8.3 & 11.6 & 2.14 & 0.3 & 9.7 & 14.6 & 1.67 & 0.05 \\
\hline Lying bouts (no./d) & 9.7 & 11.3 & 1.63 & 0.5 & 12.5 & 12.5 & 0.92 & 0.9 \\
\hline Lying bout duration (min/bout) & 62.9 & 70.0 & 6.56 & 0.5 & 46.2 & 51.7 & 2.94 & 0.2 \\
\hline
\end{tabular}

${ }^{1}$ Replacements defined on the basis of an algorithm that identified when 1 cow (the "reactor") exits a feed bin and another (the "actor") takes her place within a period of $26 \mathrm{~s}$.

fever. In other aspects, our results differ from earlier findings. For example, Sepúlveda-Varas et al. (2016) found that cows with mastitis had decreased feeding rate in the days before diagnosis, but in the current study we found increased feeding rate for cows with $1 \mathrm{~d}$ of fever. Also, we found shorter feeding times for fever cows (both $1 \mathrm{~d}$ and multi-day fever), but some other work has not found differences in feeding time for sick cows (e.g., for metritis; Neave et al., 2018). Mastitis and metritis may be painful (Fitzpatrick et al., 2013; Barragan et al., 2018), and this pain may result in behavioral change. Future studies should attempt to isolate the effect of pain, for example by comparing sick animals with and without treatment using effective analgesics.

Our study had several limitations. One is that cows had occasional missing BT recordings, so some days with fever may have been missed. To minimize this risk, only cows with no missing values before and after the days of fever were included (details on which data were missing are provided in Supplemental Table S1, https: //doi.org/10.3168/jds.2018-15969). Assessing temperatures only once daily limited our ability to analyze behavioral change in relation to the onset of fever in greater detail; we encourage future work with continuous assessment of BT.

A second limitation of our study is that some fever bouts were detected on days with high ambient temperatures. Heat stress is defined as increased BT due to environmental conditions (e.g., bulb temperature, humidity; Dikmen and Hansen, 2009) rather than fever. High environmental temperatures can cause behavioral changes, including increased time standing (Cook et al., 2007; Nordlund et al., 2019). We may have classified cows as having a fever even though the BT elevation was a result of the high ambient temperature only; we suggest that this risk is low as we measured rectal temperature before noon when ambient temperatures tend to be lower in our facility. We suggest that future research should focus on periods of both hot and cool weather to better understand how behavioral changes interact with environmental conditions.

\section{CONCLUSIONS}

Cows with one and multiple days of fever spent less time feeding than healthy animals. This behavioral difference is consistent with the expression of sickness behavior observed during responses to clinical disease.

\section{ACKNOWLEDGMENTS}

We thank all the staff and students of the UBC Dairy Education and Research Centre who helped with data collection in this experiment, with a special thanks to Julie Huzzey (UBC Animal Welfare Program). We thank Boehringer Ingelheim Animal Health (Burlington, Ontario, Canada) for their generous donation to support the various students that helped with this trial. General funding for UBC's Animal Welfare Program comes from an Natural Sciences and Engineering Research Council of Canada Industrial Research Chair with industry contributions from the Dairy Farmers of Canada (Ottawa, ON, Canada), Saputo Inc. (Montreal, QC, Canada), British Columbia Dairy Association (Burnaby, BC Canada), Alberta Milk (Edmonton, AB, Canada), Intervet Canada Corporation (Kirkland, QC, Canada), Boehringer Ingelheim Animal Health (Burlington, ON, Canada), BC Cattle Industry Development Fund (Kamloops, BC, Canada), The Semex Alliance (Guelph, ON, Canada), Lactanet (Sainte-Anne-deBellevue, QC, Canada), Dairy Farmers of Manitoba (Winnipeg, MB, Canada), and the Saskatchewan Milk Marketing Board (Regina, SK, Canada). The authors have not stated any conflicts of interest.

\section{REFERENCES}

Barragan, A. A., J. M. Piñeiro, G. M. Schuenemann, P. J. RajalaSchultz, D. E. Sanders, J. Lakritz, and S. Bas. 2018. Assessment of daily activity patterns and biomarkers of pain, inflammation, and 
stress in lactating dairy cows diagnosed with clinical metritis. J. Dairy Sci. 101:8248-8258. https://doi.org/10.3168/jds.2018-14510.

Bleeker-Rovers, C. P., J. W. M. van der Meer, and N. J. Beeching. 2009. Fever. Medicine (Baltimore) 37:28-34. https://doi.org/10 .1016/j.mpmed.2008.10.007.

Burfeind, O., M. A. G. von Keyserlingk, D. M. Weary, D. M. Veira, and W. Heuwieser. 2010. Short communication: Repeatability of measures of rectal temperature in dairy cows. J. Dairy Sci. 93:624627. https://doi.org/10.3168/jds.2009-2689.

CCAC (Canadian Council on Animal Care). 2009. CCAC Guidelines on the Care and Use of Farm Animals in Research, Teaching and Testing, Canadian Council. Anim. Care, Ottawa, ON, Canada.

Chapinal, N., D. M. Veira, D. M. Weary, and M. A. G. von Keyserlingk. 2007. Technical note: Validation of a system for monitoring individual feeding and drinking behavior and intake in group-housed cattle. J. Dairy Sci. 90:5732-5736. https://doi.org/ 10.3168/jds.2007-0331.

Cook, N. B., R. L. Mentink, T. B. Bennett, and K. Burgi. 2007. The effect of heat stress and lameness on time budgets of lactating dairy cows. J. Dairy Sci. 90:1674-1682. https://doi.org/10.3168/ jds.2006-634.

Dikmen, S., and P. J. Hansen. 2009. Is the temperature-humidity index the best indicator of heat stress in lactating dairy cows in a subtropical environment? J. Dairy Sci. 92:109-116. https://doi .org/10.3168/jds.2008-1370

Fitzpatrick, C. E., N. Chapinal, C. S. Petersson-Wolfe, T. J. DeVries, D. F. Kelton, T. F. Duffield, and K. E. Leslie. 2013. The effect of meloxicam on pain sensitivity, rumination time, and clinical signs in dairy cows with endotoxin-induced clinical mastitis. J. Dairy Sci. 96:2847-2856. https://doi.org/10.3168/jds.2012-5855.

Hart, B. L. 1988. Biological basis of the behavior of sick animals. Neurosci. Biobehav. Rev. 12:123-137. https://doi.org/10.1016/S0149 -7634(88)80004-6.

Huzzey, J. M., D. M. Veira, D. M. Weary, and M. A. G. von Keyserlingk. 2007. Prepartum behavior and dry matter intake identify dairy cows at risk for metritis. J. Dairy Sci. 90:3220-3233. https:/ /doi.org/10.3168/jds.2006-807.

Huzzey, J. M., M. A. G. von Keyserlingk, and D. M. Weary. 2005. Changes in feeding, drinking, and standing behavior of dairy cows during the transition period. J. Dairy Sci. 88:2454-2461. https:// doi.org/10.3168/jds.S0022-0302(05)72923-4.

Huzzey, J. M., D. M. Weary, B. Y. F. Tiau, and M. A. G. von Keyserlingk. 2014. Short communication: Automatic detection of social competition using an electronic feeding system. J. Dairy Sci. 97:2953-2958. https://doi.org/10.3168/jds.2013-7434.

Johnston, C., and T. J. DeVries. 2018. Short communication: Associations of feeding behavior and milk production in dairy cows. J. Dairy Sci. 101:3367-3373. https://doi.org/10.3168/jds.2017-13743.

Kaufman, E. I., S. J. LeBlanc, B. W. McBride, T. F. Duffield, and T. J. DeVries. 2016. Short communication: Association of lying behavior and subclinical ketosis in transition dairy cows. J. Dairy Sci. 99:7473-7480. https://doi.org/10.3168/jds.2016-11185.

King, M. T. M., S. J. LeBlanc, E. A. Pajor, T. C. Wright, and T. J. DeVries. 2018. Behavior and productivity of cows milked in automated systems before diagnosis of health disorders in early lactation. J. Dairy Sci. 101:4343-4356. https://doi.org/10.3168/ jds.2017-13686.

LeBlanc, S. 2010. Monitoring metabolic health of dairy cattle in the transition period. J. Reprod. Dev. 56(S):S29-S35. https://doi.org/ 10.1262/jrd.1056S29.

Ledgerwood, D. N., C. Winckler, and C. B. Tucker. 2010. Evaluation of data loggers, sampling intervals, and editing techniques for measuring the lying behavior of dairy cattle. J. Dairy Sci. 93:51295139. https://doi.org/10.3168/jds.2009-2945.

Lomb, J., H. W. Neave, D. M. Weary, S. J. LeBlanc, J. M. Huzzey, and M. A. G. von Keyserlingk. 2018. Changes in feeding, social, and lying behaviors in dairy cows with metritis following treatment with a nonsteroidal anti-inflammatory drug as adjunctive treatment to an antimicrobial. J. Dairy Sci. 101:4400-4411. https://doi.org/10 $.3168 /$ jds.2017-13812
Mulligan, F. J., and M. L. Doherty. 2008. Production diseases of the transition cow. Vet. J. 176:3-9. https://doi.org/10.1016/j.tvjl.2007 .12 .018 .

Neave, H. W., J. Lomb, M. A. G. von Keyserlingk, A. Behnam-Shabahang, and D. M. Weary. 2017. Parity differences in the behavior of transition dairy cows. J. Dairy Sci. 100:548-561. https://doi.org/ 10.3168/jds.2016-10987.

Neave, H. W., J. Lomb, D. M. Weary, S. J. LeBlanc, J. M. Huzzey, and M. A. G. von Keyserlingk. 2018. Behavioral changes before metritis diagnosis in dairy cows. J. Dairy Sci. 101:4388-4399. https:// doi.org/10.3168/jds.2017-13078.

Nordlund, K. V., P. Strassburg, T. B. Bennett, G. R. Oetzel, and N. B. Cook. 2019. Thermodynamics of standing and lying behavior in lactating dairy cows in freestall and parlor holding pens during conditions of heat stress. J. Dairy Sci. 102:6495-6507. https://doi .org/10.3168/jds.2018-15891.

NRC. 2001. Nutrient Requirements of Dairy Cattle. 7th rev. ed. Natl Acad. Sci, Washington, DC.

Pecchi, E., M. Dallaporta, A. Jean, S. Thirion, and J. D. Troadec. 2009. Prostaglandins and sickness behavior: Old story, new insights. Physiol. Behav. 97:279-292. https://doi.org/10.1016/j .physbeh.2009.02.040.

Proudfoot, K. L., D. M. Veira, D. M. Weary, and M. A. G. von Keyserlingk. 2009. Competition at the feed bunk changes the feeding, standing, and social behavior of transition dairy cows. J. Dairy Sci. 92:3116-3123. https://doi.org/10.3168/jds.2008-1718.

Sepúlveda-Varas, P., K. L. Proudfoot, D. M. Weary, and M. A. G. von Keyserlingk. 2016. Changes in behaviour of dairy cows with clinical mastitis. Appl. Anim. Behav. Sci. 175:8-13. https://doi.org/10 .1016/j.applanim.2014.09.022.

Shakhar, K., and G. Shakhar. 2015. Why do we feel sick when infected - Can altruism play a role? PLoS Biol. 13:e1002276. https:/ /doi.org/10.1371/journal.pbio.1002276.

Suthar, V., O. Burfeind, S. Bonk, R. Voigtsberger, C. Keane, and W. Heuwieser. 2012. Factors associated with body temperature of healthy Holstein dairy cows during the first 10 days in milk. J. Dairy Res. 79:135-142. https://doi.org/10.1017/S0022029911000896.

Sutherland, L.-A., R. J. F. Burton, J. Ingram, K. Blackstock, B. Slee, and N. Gotts. 2012. Triggering change: towards a conceptualisation of major change processes in farm decision-making. J. Environ. Manage. 104:142-151. https://doi.org/10.1016/j.jenvman .2012.03.013.

Tizard, I. 2008. Sickness behavior, its mechanisms and significance 9:87-99. doi:https://doi.org/10.1017/S1466252308001448.

UBC Animal Welfare Program. 2013. UBC Animal Welfare Program: SOP - HOBO Data Loggers. pp. 1 - 23. University of British Columbia, Vancouver, Canada. Accessed Mar. 13, 2018. http:/ /lfs-awp.sites.olt.ubc.ca/files/2013/11/SOP-HOBO-Datalogger -november-2013.pdf.

Waldron, M. R., T. Nishida, B. J. Nonnecke, and T. R. Overton. 2003. Effect of lipopolysaccharide on indices of peripheral and hepatic metabolism in lactating cows. J. Dairy Sci. 86:3447-3459. https:// doi.org/10.3168/jds.S0022-0302(03)73949-6.

Wenz, J. R., D. A. Moore, and R. Kasimanickam. 2011. Factors associated with the rectal temperature of Holstein dairy cows during the first 10 days in milk. J. Dairy Sci. 94:1864-1872. https://doi.org/ 10.3168/jds.2010-3924.

Zhao, F. F., T. Y. Wu, H. R. Wang, L. Y. Ding, G. Ahmed, H. W. Li, W. Tian, and Y. Z. Shen. 2018. Jugular arginine infusion relieves lipopolysaccharide-triggered inflammatory stress and improves immunity status of lactating dairy cows. J. Dairy Sci. 101:5961-5970. https://doi.org/10.3168/jds.2017-13850

\section{ORCIDS}

M. A. G. von Keyserlingk (ํ) https://orcid.org/0000-0002-1427-3152 D. M. Weary @ https://orcid.org/0000-0002-0917-3982 